\title{
The validity and reliability of DSM-5 separation anxiety disorder severity scale-adult form
}

\author{
Emine Ozge Coldur ${ }^{\oplus},{\text { Fikret Poyraz } \text { Cokmus }^{2}}^{\oplus}$, Didem Suculluoglu Dikici ${ }^{\oplus}$, Omer Aydemir $^{3 \oplus}$ \\ 'Kusadasi State Hospital, Department of Psychiatry, Aydin - Turkey \\ ${ }^{2}$ Manisa Mental Health and Disease Hospital, Department of Psychiatry, Manisa - Turkey \\ ${ }^{3}$ Manisa Celal Bayar University, Faculty of Medicine, Department of Psychiatry, Manisa - Turkey
}

\begin{abstract}
Objective: This study aimed to assess the validity and reliability of the Turkish version of the DSM- 5 Separation Anxiety Disorder Severity Scale-Adult Form.

Method: The scale was prepared by translation and back-translation of the DSM-5 Separation Anxiety Disorder Severity ScaleAdult Form. The study group consisted of 81 patients treated in the adult psychiatry unit, diagnosed with a separation anxiety disorder $(n=36)$ or panic disorder $(n=45)$, and 80 healthy controls. For the assessment, DSM-5 Separation Anxiety Disorder Severity Scale-Adult Form along with the Adult Separation Anxiety Questionnaire was used.

Results: The Cronbach alpha internal consistency coefficient was 0.93 and the item-total score correlation coefficients were between 0.58 and 0.85 . Test-retest correlation coefficient was calculated as $r=0.989$. A single factor that explains $62.77 \%$ of the variance was obtained. The factor loads of the scale items were found between 0.65 and 0.89 . In the confirmatory factor analysis, the goodness-offit index were found to be RMSEA $=0.09, \mathrm{CFI}=0.94$ and $\chi^{2} / \mathrm{df}=3.34$. The scale showed a strong positive correlation with the Adult Separation Anxiety Questionnaire $(r=0.76, \mathrm{p}<0.001)$.

Conclusion: It was concluded that the Turkish version of DSM-5 Separation Anxiety Disorder Severity Scale-Adult Form can be used as a valid and reliable tool both in clinical practice and for research purposes.
\end{abstract}

Keywords: Panic disorder, reliability, separation anxiety, validity

\section{INTRODUCTION}

In the late nineties, a group of Australian authors suggested that separation anxiety disorder (SAD) may have been a separate diagnosis in adulthood (1). Studies have shown that separation anxiety disorder, which was thought to be limited to childhood and adolescence in the past, continues or emerges in adulthood as well (2-4).

Separation anxiety is a developmentally inappropriate state of extreme fear and anxiety when it comes to separation from the attachment object or the expectation of separation from it. In childhood separation anxiety disorder, parents are the most important attachment figures and common separation behaviors include crying, tantrums, and school refusal. On the other hand, adults with separation anxiety have intense fears that their attachment figures (usually their spouse or child) will be harmed, and therefore make a superior effort to stay in close contact with them, even if it is laborious and inappropriate (5).

SAD was placed in the Anxiety Disorders section of DSM-5, the initial age restriction was removed, the

How to cite this article: Coldur EO, Cokmus FP, Suculluoglu Dikici D, Aydemir O. The validity and reliability of DSM-5 separation anxiety disorder severity scale-adult form. Dusunen Adam The Journal of Psychiatry and Neurological Sciences 2020;33:237-243.

Correspondence: Fikret Poyraz Cokmus, Manisa Mental Health and Disease Hospital, Department of Psychiatry, 814 Street No: 28, Manisa - Turkey E-mail: fikretpoyrazcokmus@hotmail.com

Received: April 02, 2020; Revised: April 16, 2020; Accepted: June 09, 2020 
condition of "the symptoms last for at least 6 months" was added, and the diagnosis criteria were adjusted for adults (6). This change is based on the findings of epidemiological studies that have revealed an unexpectedly high prevalence of individuals whose SAD symptoms begin after their teenage years. The lifetime prevalence of SAD was determined as $6.6 \%$ in a study (NCS-R) conducted in the USA with 5692 participants, and it was reported that the symptoms appeared for the first time in adulthood in the vast majority of patients (77.5\%) (2). Conducted by evaluating the data from World Mental Health Researches of the World Health Organization (WHO) the study revealed that in the community-based population of approximately 39 thousand people in 18 countries the prevalence of SAD was $4.8 \%$ and that $43.1 \%$ of the sample group was having the disease after the age of 18 (3).

Although it is known that SAD is commonly associated with panic disorder (7) or agoraphobia in previous studies, studies have revealed a wide range of comorbidity such as complicated grief (6\%) (8) and posttraumatic stress disorder $(18 \%)(9,10)$. At the same time, it was shown that ongoing SAD facilitates the development of comorbid disorders such as panic disorder, anxiety disorders such as agoraphobia and depression, which commonly start in adulthood (11). In various studies, it was determined that $\mathrm{SAD}$ significantly impairs social and occupational functionality, especially in patients with another comorbid psychiatric disorder (3). Allowing adults to be diagnosed with SAD in DSM-5 will encourage research on the developmental continuity of separation anxiety, family clustering, etiology, and treatment response (10).

New assessment tools are needed to assess anxiety disorders in recent cases. To this end, the American Psychiatric Association created new dimensional scales for DSM-5 that cover all anxiety disorders and are based on three different and independent models (cognition, physiology, and behavior) proposed by Lang (12) for anxiety disorders. In the literature, there are the Adult Separation Anxiety Questionnaire (ASA), which investigates separation anxiety symptoms in adulthood, and the Separation Anxiety Symptom Inventory (SASI), which questions the symptoms of separation anxiety in adults in the past (13). In addition, the Turkish validity and reliability of the Structured Clinical Interview for Separation Anxiety Symptoms, which was formed through developing age-appropriate definitions of childhood SAD symptoms in order to evaluate adult separation anxiety symptoms (14). Separation Anxiety
Disorder Severity Scale (SADSS) is a self-report scale consisting of 10 items that is used to determine the severity of separation anxiety symptoms in adulthood and provides practical measurement. Compared to the other scales mentioned above, SADSS is thought to be helpful for clinicians in questioning SAD symptoms and measuring SAD severity, since it provides ease of application due to its low number of items, and is prepared in accordance with DSM-5 diagnostic criteria.

In this study, it was aimed to introduce the SADDS was prepared for DSM-5 by the American Psychiatric Association, into Turkish by showing its validity and reliability. In addition, SADSS was aimed to distinguish between patient and healthy control groups and to test its validity with ASA.

\section{METHOD}

\section{Translation Procedure}

The translation of the scale was carried out by a team of physicians from the Department of Psychiatry at Manisa Celal Bayar University. The comprehensibility of the scale questions was tested by the same team and turned into a text that was agreed upon. The scale was later translated back into English by Ö.A. This translation was evaluated and checked by the team that continued to work. As a result, the expressions thought to represent the original items best were selected and the comprehensibility of the scale questions was tested. After discussing the translations, necessary changes were made and the scale was finalized.

\section{Sample Group}

Before the study, ethics committee approval was obtained from the Scientific Research Ethics Committee of Manisa Celal Bayar University (03/12/2014-20.478.486-391). The patient group of the study comprised of the patients admitted to psychiatric outpatient clinics between January 2018 and January 2020 in three centers and met the specified criteria. The sample group of the study consisted of 45 panic disorders (PD) and 36 SAD and 80 healthy controls (HC), diagnosed with the Structured Clinical Interview for DSM-5 Disorders (SCID-5/CV) (15). 14 patients and $18 \mathrm{HC}$ were excluded from the study because they under-filled the given scales. Written consent was obtained from all participants before the study. The HC group consisted of volunteers who did not have any psychiatric disorder as a result of SCID-5/ CV (15), and the patient group consisted of volunteers who did not have any psychiatric disorder other than panic disorder or adult SAD as a result of SCID-5/CV 
(15). For both groups, the presence of a physical or neurological diseases requiring continuous treatment and mental retardation were determined as exclusion criteria from the research. The volunteers surveyed were expected to be between the ages of 18-65, to have the mental capacity to fill the scale and to follow the research instructions.

\section{Measures}

Sociodemographic Data Form: The sociodemographic data form is composed of questions including age, gender, occupation, marital status, financial status, educational attainment, hospitalization history and number of hospital stay if available, additional disease presence, family history of psychiatric disease and disease duration

Adult Separation Anxiety Questionnaire (ASA): The scale was developed by Manicavasagar et al. (16) to determine the symptoms of separation anxiety. The Turkish adaptation study of the scale was carried out by Dirioz (13) on an adult sample of psychiatric patients aged 18-65 and a healthy control group. It is composed of 27 items and provides a four-point Likert-type assessment (Very often, often, rarely, never). In the validity and reliability studies of the ASA Turkish form, the Cronbach alpha coefficient was found between 0.93 and the item-total correlation coefficients between 0.29-0.76.

DSM-5 Separation Anxiety Disorder Severity Scale (SADSS): DSM-5 SADSS is a 10-item self-rating scale prepared by the American Psychiatric Association and provides a five-point Likert-type assessment $(0=$ never, $4=$ all the time). Participants are asked to rate the scale by considering their thoughts, feelings and behaviors in the last seven days. The scores from the scale items determine the severity of separation anxiety. The scores from the scale are between 0 and 40 , and high scores indicate severe separation anxiety. After the total score is obtained, the "average total score" is calculated by dividing the scale by the total number of items (10). If the resulting score is fractional, it is rounded to the nearest value and re-scored as (0) none, (1) mild, (2) moderate, (3) severe, (4) extremely severe.

\section{Statistical Analysis}

The statistical assessment includes data from 161 volunteers. It was evaluated by Saphiro-Wilk test to see whether the data showed normal distribution or not. Chi-square test for categorical variables, t-test in independent groups in numerical variables and oneway variability analysis (ANOVA) were applied to examine the relationship between groups. In the reliability analysis, Cronbach alpha internal consistency analysis of both the sum and sub-items of the scales were conducted. For test-retest reliability, research scales were re-applied two weeks after the first application to a total of 80 volunteers, 40 from the patient group and 40 from the HC group, and the testretest reliability was determined by calculating the correlation coefficient between the two applications. Exploratory factor analysis and concurrent validity tests were used in validity analysis. Kaiser-Meyer-Olkin (KMO) coefficient and Bartlett's test of Sphericity were applied to evaluate the appropriation of the data for factor analysis and the sample size. ASA was used to determine the co-validity of DSM-5 SADSS. Exploratory factor analysis was carried out by applying varimax rotation according to the main components method, and factors with an eigenvalue (self-worth) of 1 and above were evaluated. Items with factor loads of 0.4 and above among their factor structures were assessed. AMOS 23 version (17) was used for the confirmatory factor analysis procedure to be applied in order to test the construct validity of the Turkish version of DSM-5 SADSS. In the confirmatory factor analysis, the relative chi-square obtained by dividing the root mean square error of approximation (RMSEA), comparative fit index (CFI) and chi-square fit index by degrees of freedom (2/df) was used. In the statistical analysis, SPSS for Windows 22 statistical package program was used to assess data other than confirmatory factor analysis (18).

\section{RESULTS}

The study was conducted with a total of 161 volunteers, including $36 \mathrm{SAD}, 45$ with PD and $81 \mathrm{HC}$. Between the groups, years of education ( $\mathrm{HC}>\mathrm{PD}>\mathrm{SAD}$ ) $(\mathrm{F}[2.158]=13.387, \mathrm{p}<0.001)$, age $(\mathrm{PD}>\mathrm{HC}>\mathrm{SAD})$ $(\mathrm{F}[2.158]=5.056, \mathrm{p}=0.007)$ and presence of psychiatric disease in the $(\mathrm{PD}>\mathrm{SAD}>\mathrm{HC})\left(\chi^{2}[2]=12.106, \mathrm{p}=0.002\right)$ were found to be a statistically different, there was no statistical difference in gender $\left(\chi^{2}[2]=1.633, \mathrm{p}=0.442\right)$ and the presence of additional disease $\left(\chi^{2}[2]=1.238\right.$, $\mathrm{p}=0.538)$, there was no statistically significant difference. The DSM-5 SADSS score of the SAD group was found to be $20.89 \pm 8.22$, the PD group as $11.47 \pm 8.28$, and the HC group as $2.77 \pm 3.62$. A statistically significant difference was found between the groups $(\mathrm{F}[2.158]=104.088, \mathrm{p}<0.001)$. The total score of the SAD group was $46.08 \pm 11.32$, the total score of the PD group was $29.33 \pm 12.79$, and the total score of the HC group was $14.12 \pm 6.42$. There was a 
statistically significant difference between the groups $(\mathrm{F}[2.158]=136.659, \mathrm{p}<0.001)$. Compared to the clinical characteristics of the PD and SAD groups, the disease duration $(\mathrm{PD}>\mathrm{SAD})(\mathrm{t}[79]=1.21, \mathrm{p}=0.016)$ and hospitalization history $(\mathrm{PD}>\mathrm{SAD})\left(\chi^{2}[1]=4.263\right.$, $\mathrm{p}=0.039)$ while there was a significant difference between the groups, no significant difference was found in terms of the number of hospital stay $(\mathrm{t}[79]=2.450, \mathrm{p}=0.230)$. The Sociodemographic and clinical characteristics of both groups are shown in Table 1.

\section{Validity Analysis}

The Kaiser-Meyer-Olkin (KMO) value used to assesses the adequacy of the data set for factor analysis was 0.919 and the Bartlett coefficient was $1135.782(\mathrm{p}<0.001)$, and these results were considered adequate for factor analysis. As a result of the exploratory factor analysis, one factor with an eigenvalue value of 1 was determined. This one factor explains $62.77 \%$ of the total variance. When the factor loads were examined, no item was found under 0.40 load value. The factor loads of the scale items ranged from 0.65 to 0.89 . The data are given in Table 4 . In the confirmatory factor analysis results of DSM-5 SADSS, RMSEA $=0.09, \mathrm{CFI}=0.94$ and $\chi^{2} / \mathrm{df}=3.34$. The data are given in Table 5. ASA was used to determine the co-validity of DSM-5 SADSS. SADSS showed a strong positive correlation with ASA $(r=0.76, \mathrm{p}<0.001)$.

\section{Reliability Analysis}

The Cronbach alpha coefficient of the scale was found to be 0.93 in the internal consistency analysis of DSM-5 SADSS total score and sub-scores. When the item is deleted, the Cronbach alpha values of the scale items range between $0.92-0.93$. Item total score correlation coefficients were found between 0.58 and 0.85 $(\mathrm{p}<0.001)$. The data is shown in Table 2. For test-retest analysis, SADSS was applied to 80 people with 40 patients and $40 \mathrm{HC}$ at two-week intervals. Correlation values range between $0.914-0.990(\mathrm{p}<0.001)$. Test-retest correlation coefficient was calculated as $r=0.989$ for the SADDS total score. The correlation coefficients of the scale items are given in Table 3.

\section{DISCUSSION}

In this study, psychometric features of the adult form of SADSS a self-reporting scale developed to assess the severity of SAD according to DSM-5 criteria, were examined. The demographic data differences

Table 1: Sociodemographic and clinical variable characteristics of patient groups and healthy control groups

\begin{tabular}{|c|c|c|c|c|c|c|c|c|}
\hline \multirow[b]{2}{*}{ Age (Mean $\pm S D$ ) } & \multicolumn{2}{|c|}{ SAD $(n=36)$} & \multicolumn{2}{|c|}{$P D(n=45)$} & \multicolumn{2}{|c|}{ SD $(n=80)$} & \multirow[b]{2}{*}{$F(2.158)=5.056$} & \multirow{2}{*}{$\begin{array}{c}\mathbf{p} \\
0.007\end{array}$} \\
\hline & 27.83 & 11.49 & 34.51 & 11.80 & 34.07 & 9.56 & & \\
\hline \multirow[t]{2}{*}{ Education (year) (Mean \pm SD) } & 11.53 & 3.51 & 11.67 & 3.21 & 14.45 & 3.63 & $F(2.158)=13.387$ & $<0.001$ \\
\hline & $\mathbf{n}$ & $\%$ & $\mathbf{n}$ & $\%$ & $\mathbf{n}$ & $\%$ & & \\
\hline Gender & & & & & & & $\chi^{2}(2)=1.633$ & 0.442 \\
\hline Man & 11 & 30.6 & 20 & 44.4 & 31 & 38.8 & & \\
\hline Woman & 25 & 69.4 & 25 & 55.6 & 49 & 61.3 & & \\
\hline Family history of psychiatric disease & & & & & & & $\chi^{2}(2)=12.106$ & 0.002 \\
\hline Yes & 19 & 52.8 & 24 & 53.3 & 21 & 26.3 & & \\
\hline No & 17 & 47.2 & 21 & 46.7 & 59 & 73.7 & & \\
\hline Presence of additional disease & & & & & & & $\chi^{2}(2)=1.238$ & 0.538 \\
\hline Yes & 8 & 22.2 & 6 & 13.3 & 16 & 20.0 & & \\
\hline No & 28 & 77.8 & 39 & 86.7 & 64 & 80.0 & & \\
\hline Hospitalization history & & & & & & & $\chi^{2}(1)=4.263$ & 0.039 \\
\hline Yes & 0 & 0 & 5 & 11.1 & & & & \\
\hline No & 36 & 100.0 & 40 & 88.9 & & & & \\
\hline SADSS total score (Mean \pm SD) & 20.89 & 8.22 & 11.47 & 8.28 & 2.77 & 3.62 & $F(2.158)=104.088$ & $<0.001$ \\
\hline ASA total score (Mean \pm SD) & 46.08 & 11.32 & 29.33 & 12.79 & 14.12 & 6.42 & $F(2.158)=136.659$ & $<0.001$ \\
\hline Number of hospital stay (Mean \pm SD) & 0 & 0 & 0.24 & 1.21 & & & $t(79)=2.450$ & 0.230 \\
\hline Disease duration (year) (Mean $\pm S D$ ) & 2.56 & 2.96 & 5.14 & 5.73 & & & $\mathrm{t}(79)=1.21$ & 0.016 \\
\hline
\end{tabular}


Table 2: Item scores, item total score correlation coefficients and Cronbach alfa values when the item eliminated

\begin{tabular}{|c|c|c|c|c|}
\hline & \multicolumn{2}{|c|}{ Item scores } & \multirow{2}{*}{$\begin{array}{l}\text { Item total score } \\
\text { correlation coefficient }\end{array}$} & \multirow{2}{*}{$\begin{array}{c}\text { Cronbach alfa values } \\
\text { when the item eliminated }\end{array}$} \\
\hline & Mean & SD & & \\
\hline SADSS-1 & 0.92 & 1.24 & 0.78 & 0.92 \\
\hline SADSS-2 & 1.16 & 1.23 & 0.85 & 0.92 \\
\hline SADSS-3 & 1.28 & 1.31 & 0.70 & 0.93 \\
\hline SADSS-4 & 0.81 & 1.19 & 0.75 & 0.92 \\
\hline SADSS-5 & 0.99 & 1.33 & 0.79 & 0.92 \\
\hline SADSS-6 & 0.63 & 0.98 & 0.66 & 0.93 \\
\hline SADSS-7 & 0.88 & 1.20 & 0.62 & 0.93 \\
\hline SADSS-8 & 0.94 & 1.29 & 0.81 & 0.92 \\
\hline SADSS-9 & 1.03 & 1.25 & 0.78 & 0.92 \\
\hline SADSS-10 & 0.61 & 1.15 & 0.58 & 0.93 \\
\hline SADSS-total & 9.25 & 9.64 & & \\
\hline
\end{tabular}

SADSS: Separation Anxiety Disorder Severity Scale, SD: Standard deviation

Table 3: Test-retest correlation coefficients

\begin{tabular}{ll} 
& $\mathbf{r}^{*}$ \\
\hline SADSS-1 & 0.939 \\
SADSS-2 & 0.967 \\
SADSS-3 & 0.942 \\
SADSS-4 & 0.987 \\
SADSS-5 & 0.968 \\
SADSS-6 & 0.959 \\
SADSS-7 & 0.914 \\
SADSS-8 & 0.990 \\
SADSS-9 & 0.959 \\
SADSS-10 & 0.969 \\
SADSS-total & 0.989 \\
\hline
\end{tabular}

SADSS: Separation Anxiety Disorder Severity Scale

*Pearson correlation coefficient

Table 4: DSM-5 SADSS exploratory factor structure

Factor loads of items

\begin{tabular}{ll}
\hline SADSS-1 & 0.83 \\
SADSS-2 & 0.89 \\
SADSS-3 & 0.76 \\
SADSS-4 & 0.80 \\
SADSS-5 & 0.84 \\
SADSS-6 & 0.73 \\
SADSS-7 & 0.69 \\
SADSS-8 & 0.86 \\
SADSS-9 & 0.73 \\
SADSS-10 & 0.65 \\
\hline
\end{tabular}

SADSS: Separation Anxiety Disorder Severity Scale

(educational attainment) detected between the groups do not pose a problem in terms of study design.
Table 5: Confirmatory factor analysis results for SADSS

\begin{tabular}{lccc} 
& RMSEA & CFI & $\boldsymbol{\chi}^{\mathbf{2} / \mathbf{d f}}$ \\
\hline SADSS & 0.09 & 0.94 & 3.34 \\
\hline SADSS: Separation Anxiety Disorder Severity Scale, RMSEA: The root mean \\
square error of approximation, CFI: Comparative fit index, $\chi^{2} / \mathrm{df}:$ chi-square fit \\
index to degrees of freedom ratio
\end{tabular}

The Cronbach alpha coefficient for the total SADSS total is 0.93 and it is considered to be a good internal consistency indicator. The changes in the Cronbach's alpha coefficient value when each item of the scale was excluded from the scale separately were calculated, and the values were found between 0.92 and 0.93 . The values obtained by excluding each item are not higher than the value obtained from the total of the scale. Therefore, it can be said that scale items are highly stable. If the score to be obtained from a test is to be used for comparison between groups, 0.80 is sufficient standard for reliability, whereas if an individual assessment is to be made, it is 0.90 for minimum standard and 0.95 for the desired standard (19). Considering these standards, analysis for internal consistency reliability show that the reliability of SADSS is high enough for all applications.

Items having total correlations of 0.30 and higher are known to well distinguish between individuals having the measured feature and individuals without it (19). Item-total correlation values for all items of the SADSS Turkish form range between 0.58 and 0.85 . This is a high level of correlation, indicating that the items exemplify similar behaviors and that the internal consistency of the test is high. It was understood that the consistency of each item with the whole scale was quite good and the reliability of the scale was supported. In the validity-reliability study of DSM-5 SADSS in the 
Netherlands in 2016 (20), the Cronbach alpha value of the sample consisting of 253 men was 0.90 , and the Cronbach alpha value of the sample consisting of 283 women was 0.93 . In the validity-reliability study of DSM-5 SADSS in childhood period (21) in our country, the Cronbach alpha value of the sample was found to be 0.932 , and the item-total score correlation coefficients were between $0.40-0.87$. Compared with the other scales used in SAD in adulthood period in our country, the ASA (Cronbach's alpha coefficient 0.93, item-total correlation coefficients $0.29-0.76$ ) and the adulthood sub-section of the Structured Clinical Interview for Separation Anxiety (14) (Cronbach alpha value of 0.59, item total score correlations $0.23-0.41$ ), it is seen that SADSS has an internal consistency at least as much as other scales, even better than other scales. The findings show that each item of SADSS is compatible within itself and within the whole scale, and complementary to each other. Test-retest correlation values ranged from 0.914 to 0.990 as a result of SADSS applied to a total of 80 people, 40 patients with $40 \mathrm{HC}$, at intervals of two weeks $(p<0.001)$. Considering all these data, it was revealed that the reliability of the scale is achieved.

For factor analysis, the case/scale item ratio is recommended to be at least 5, ideally 10 (19). This ratio, which was 8.1 in our study, can be said to be at a good level. In the exploratory factor analysis applied to determine the factor structure of the SADSS items; a single-factor solution was obtained similar to the original scale, explaining $62.77 \%$ of the total variance. In this study, the highest factor load of the SADSS items was 0.89 in item 2 , and the lowest factor load was 0.65 in item 10. The variance value obtained from each item is over 0.40 . When all findings are evaluated, exploratory factor analysis reveals that SADSS has a good construct validity.

When the SAD $(20.89 \pm 8.22)$, PD $(11.47 \pm 8.28)$ and SK $(2.77 \pm 3.62)$ groups were compared in terms of the total mean scores of SADSS, it was determined that they were statistically significantly different from each other $(\mathrm{F}[2.158]=104.088, \mathrm{p}<0.001)$. Similar statistical significance is also valid for ASA $(\mathrm{F}[2.158]=136.659$, $\mathrm{p}<0.001)$. When the SADSS mean scores are evaluated, it can be said that the scale can distinguish the patients from the healthy, and also distinguish the SAD from $\mathrm{PD}$ within the patient groups.

In this study, a strong positive correlation was found $(\mathrm{r}=0.76, \mathrm{p}<0.001)$, in order to contribute to the overlap validity, by comparing the mean scores of ASA and SADSS assessed in the same interview. Both the construct validity and co-validity analyzes of the scale support the validity of the scale.
One of the limitations of the study is the relatively small number of HC. Despite of this fact a number of volunteers that would allow for all analyzes were included in the study. The cross-sectional design of the study, and the lack of a follow-up work limit the interpretation of the relationship between variables. Therefore, the sensitivity of SADSS to change (sensitivity to change; determining to what extent this scale reflects this change to its own measurement by changing the pathology to which the scale is aimed to measure) was not investigated in this study and it will be useful to be examined in future studies. Thus, the value of the scale in determining the course of the scale and its capacity to predict the response to treatment can be determined. The strengths of the study are that all diagnoses were made through structured interviews and patients with comorbidities were not included.

The SAD can only be diagnosed in childhood according to the ICD-10 (22) diagnostic criteria commonly used in Europe and our country whereas it can also be diagnosed in adulthood with DSM-5. When patients with SAD were evaluated, it was observed that although some of them received treatment for comorbid diseases, the majority of them were untreated. These results show that the treatment team often does not recognize SAD (2). When panic disorder patients who received cognitive behavioral therapy (CBT) were examined, it was observed that treatment success was 4 times lower in the presence of comorbid separation anxiety disorder and it was concluded that CBT for other anxiety disorders did not reduce the symptoms of separation anxiety (23). In fact, it was found that the presence of comorbid SAD worsens the prognosis in patients with generalized anxiety disorder, social phobia, and PD who undergo CBT (10). These findings suggest that defining SAD systematically and regulating the treatment to the specific needs of these patients can improve the outcomes. In summary, the need for a measurement tool that is able to evaluate the symptoms of SAD, the symptoms of which can be confused with other anxiety disorders and its diagnosis can be overlooked, and able to examine its severity and that facilitates the treatment procedure for the clinicians.

The data obtained from the study show that SADSS is a valid and reliable measurement tool. Using this scale instead of the significantly longer ASA will facilitate the clinician's follow-up of separation anxiety disorder, which involved in routine practice with DSM-5 and was found to be common in adulthood according to many studies $(3,10)$. Due to the low number of scales evaluating SAD in our country and in particular the lack of any other scale assessing separation anxiety according to 
DSM-5 criteria, it was aimed to fill the existing gap. A scale that can be used in disease research and clinical settings, which takes a short time to complete, is easy to understand, and whose reliability and validity has been shown, was presented to Turkish psychiatry.

\begin{tabular}{|c|c|c|}
\hline \multicolumn{2}{|c|}{ Contribution Categories } & \multirow{2}{*}{$\begin{array}{l}\text { Author Initials } \\
\text { E.O.C., F.P.C., D.S.D., O.A. }\end{array}$} \\
\hline \multirow{3}{*}{ Category 1} & Concept/Design & \\
\hline & Data acquisition & E.O.C., F.P.C., O.A. \\
\hline & Data analysis/Interpretation & E.O.C., F.P.C., D.S.D., O.A. \\
\hline \multirow{2}{*}{ Category 2} & Drafting manuscript & E.O.C., F.P.C., D.S.D. \\
\hline & Critical revision of manuscript & F.P.C., O.A. \\
\hline Category 3 & Final approval and accountability & E.O.C., F.P.C., D.S.D., O.A. \\
\hline \multirow{2}{*}{ Other } & Technical or material support & E.O.C., F.P.C., D.S.D. \\
\hline & Supervision & O.A. \\
\hline
\end{tabular}

Ethics Committee Approval: This study was approved by the Scientific Research Ethics Committee of Manisa Celal Bayar University Faculty of Medicine (Date: 03/12/2014-20.478.486-391).

Informed Consent: Written informed consent obtained.

Peer-review: Externally peer-reviewed.

Conflict of Interest: The authors declared no conflict of interest.

Financial Disclosure: None declared.

\section{REFERENCES}

1. Manicavasagar V, Silove D. Is there an adult form of separation anxiety disorder? A brief clinical report. Aust N Z J Psychiatry 1997; 31:299-303.

2. Shear K, Jin R, Ruscio AM, Walters EE, Kessler RC. Prevalence and correlates of estimated DSM-IV child and adult separation anxiety disorder in the National Comorbidity Survey Replication. Am J Psychiatry 2006; 163:1074-1083.

3. Silove D, Alonso J, Bromet E, Gruber M, Sampson N, Scott K, et al. Pediatric-onset and adult-onset separation anxiety disorder across countries in the world mental health survey. Am J Psychiatry 2015; 172:647-656.

4. Manicavasagar V, Marnane C, Pini S, Abelli M, Rees S, Eapen V, Silove D. Adult separation anxiety disorder: a disorder comes of age. Curr Psychiatry Rep 2010; 12:290-297.

5. Pini S, Abelli M, Shear KM, Cardini A, Lari L, Gesi C, et al. Frequency and clinical correlates of adult separation anxiety in a sample of 508 outpatients with mood and anxiety disorders. Acta Psychiatr Scand 2010; 122:40-46.

6. American Psychiatric Association. Diagnostic and Statistical Manual of Mental Disorders Fifth Ed. (DSM-5). Koroglu E (Translator) Ankara: Hekimler Yayin Birligi, 2013.

7. Silove D, Marnane C. Overlap of symptom domains of separation anxiety disorder in adulthood with panic disorder-agoraphobia. J Anxiety Disord 2013; 27:92-97.

8. Wijeratne C, Manicavasagar V. Separation anxiety in the elderly. J Anxiety Disord 2003; 17:695-702.
9. Silove D, Momartin S, Marnane C, Steel Z, Manicavasagar V. Adult separation anxiety disorder among war-affected Bosnian refugees: comorbidity with PTSD and associations with dimensions of trauma. J Trauma Stress 2010; 23:169-172.

10. Bögels SM, Knappe S, Clark LA. Adult separation anxiety disorder in DSM-5. Clin Psychol Rev 2013; 33:663-674.

11. Milrod B, Markowitz JC, Gerber AJ, Cyranowski J, Altemus $M$, Shapiro $T$, et al. Childhood separation anxiety and the pathogenesis and treatment of adult anxiety. Am J Psychiatry 2014; 171:34-43.

12. Lang PJ. The application of psychophysiological methods to the study of psychotherapy and behavior modification: In Bergin AE, Garfield SL (editors). Handbook of Psychotherapy and Behavior Change. New York: Wiley, 1971 75-125.

13. Dirioz M, Alkin T, Yemez B, Onur E, Eminagaoglu PN. The validity and reliability of Turkish version of Separation Anxiety Symptom Inventory and Adult Separation Anxiety Questionnaire. Turk Psikiyatr Derg 2012; 23:108-116. (Turkish)

14. Dirioz M, Alkin T, Yemez B, Eminagaoglu N, Onur E. Psychometric properties of the Turkish version of the structured clinical interview for separation anxiety symptoms. Noro Psikiatri Ars 2012; 49:6-13. (Turkish)

15. Elbir M, Alp Topbas O, Bayad S, Kocabas T, Topak OZ, Cetin S, et al. Adaptation and Reliability of the Structured Clinical Interview for DSM-5-Disorders-Clinician Version (SCID-5/CV) to the Turkish Language. Turk Psikiyatri Derg 2019; 30:51.

16. Manicavasagar V, Silove D, Wagner R, Drobny J. A self-report questionnaire for measuring separation anxiety in adulthood. Compr Psychiatry 2003; 44:146-53.

17. Byrne BM. Structural equation modeling with AMOS: basic concepts, applications, and programming (multivariate applications series). Second ed., New York: Routledge/Taylor and Francis Group 2010, 396:7384.

18. IBM Corp. IBM SPSS Statistics for Windows, Version 22.0. Armonk, NY: IBM Corp., 2013.

19. Buyukozturk S. Handbook of Data Analysis for Social Sciences. Tenth ed., Ankara: Pegem Akademi Yayincilik, 2009. (Turkish)

20. Möller EL, Bögels SM. The DSM-5 Dimensional Anxiety Scales in a Dutch non-clinical sample: psychometric properties including the adult separation anxiety disorder scale. Version 2. Int J Methods Psychiatr Res 2016; 25:232-239.

21. Yalin Sapmaz S, Ozek Erkuran H, Ozturk M, Ergin D, Sen Celasin N, Karaarslan D, et al. Validity and reliability of the Turkish version of the DSM-5 Separation Anxiety Disorder Severity Scale-child form. Psychiatry Clin Psychopharmacol 2019; 29:197-203.

22. WHO. The ICD-10 classification of mental and behavioural disorders: diagnostic criteria for research. World Health Organization; 1993.

23. Aaronson CJ, Shear MK, Goetz RR, Allen LB, Barlow DH, White KS, et al. Predictors and time course of response among panic disorder patients treated with cognitive-behavioral therapy. J Clin Psychiatry 2008; 69:418-424. 